\title{
Los museos de la última frontera bonaerense y sus narrativas acerca de los pueblos indígenas
}

\author{
Mariano A. Nagy* \\ *Sección Etnología, Instituto de Ciencias Antropológicas. Facultad de \\ Filosofía y Letras, Universidad de Buenos Aires, Argentina. \\ E-mail: marianonagy@yahoo.com.ar
}

RMA

Museología

\begin{abstract}
Resumen
En este trabajo se analizan las narrativas hegemónicas acerca de los pueblos indígenas que se presentan en los museos de las ex comandancias militares, fundadas en el marco de la estrategia de avance de la frontera del Ministro de Guerra Adolfo Alsina. Dichas comandancias han devenido ciudades emplazadas en un espacio que denominamos última frontera bonaerense, cuya marca más significativa, la Zanja de Alsina, se constituiría como el último límite frente a las sociedades indígenas y la antesala de las campañas militares conocidas como la Conquista del Desierto (1879-1885). Éste espacio regional cuenta en la actualidad con una serie de museos históricos que construyen un relato acerca del origen local y nacional, de los pueblos indígenas y de las campañas militares emprendidas para su sometimiento. Se abordan aquí los casos de Puan y Trenque Lauquen, con especial énfasis en el análisis de los relatos históricos que sus museos exhiben y han logrado cristalizar en el imaginario colectivo, como así también en aquellos tópicos nunca considerados, entre los cuales el sometimiento y las posteriores trayectorias de los aborígenes de la región, devienen en el ejemplo más notable.
\end{abstract}

Palabras clave: Museos; Frontera; Campañas militares; Pueblos indígenas.

The museums of Buenos Aires last frontier and their narrative about indigenous peoples

\begin{abstract}
In this paper we analyze the hegemonic narrative about the indigenous peoples which are in the museums of the former military commands, based on the framework of War Minister Adolfo Alsina's strategy of advancing the frontier. These commands have become cities located in an area we call the last frontier of Buenos Aires, which most significant brand, the Alsina trench, would be established as the ultimate limit against the indigenous societies and the prelude to military campaigns known as the Conquest of the Desert (1879-1885). This regional space currently has a number of historical museums that make up a story about the indigenous peoples, the military campaigns undertaken for their submission, and about the local and national origin. Discussed here are the Puan and Trenque Lauquen cases, with special emphasis on the analysis of historical accounts that museums exhibit and have managed to crystallize in the collective imagination, as well as those topics never considered, among which the submission and subsequent trajectories of the aborigines of the region become the most notable example.
\end{abstract}

Keywords: Museums; Frontier; Military campaigns; Indigenous people.

En 1876, durante la presidencia de Nicolás Avellaneda y en el marco del avance de la frontera, el Ministro de Guerra Adolfo Alsina ideó un plan que consistió en establecer una serie de comandancias militares, unidas por fortines emplazados cada una legua (unos cinco kilómetros aproximadamente) y defendidos por una zanja que recibiría la denominación de su promotor: $L a$ Zanja de Alsina.

Si bien la zanja no llegó a completarse por el prematuro fallecimiento de Alsina, permite entender a la región como la "última frontera", dado que su señalamiento significó el último límite demarcatorio con el indígena, constituyendo la antesala y la estrategia posibilitadora de las campañas militares que derrotaron y sometieron a las poblaciones indígenas de Pampa y Patagonia en la conocida Conquista del Desierto (Barba 1977, Navarro Floria 2001).

La Zanja de Alsina se extendía desde Italó, al sur de Córdoba, y pasaba de norte a sur por distintas comandancias militares hoy devenidas ciudades bonaerenses: Trenque Lauquen, Guaminí, Carhué y Puán. En la actualidad, las localidades se encuentran conectadas a través de la Ruta Nacional 33 que lleva la sugerente denominación "Ruta del Desierto Dr. Adolfo Alsina".

Dicha arteria que liga las ciudades de Bahía Blanca (Buenos Aires) y Rosario (Santa Fe), corre en forma paralela, y por momentos a escasos metros, de lo que fue la Zanja de Alsina (Ver figura 1).

Cada una de las ciudades fundadas en el contexto de la 
avanzada militar sobre el territorio indígena comparte la fecha de fundación (1876) y la apertura de un museo histórico local -en el siglo XX- que ofrece un determinado relato acerca de la historia regional y nacional. Dichas instituciones presentan como tema principal el abordaje del origen de la ciudad, de modo que pueden compararse y analizarse los discursos acerca del avance estatal, la Conquista del Desierto y el sometimiento indígena, tópicos insoslayables al momento de narrar su propia historia.

Por ello, entendemos que éstos pueden agruparse como museos de frontera, categoría que implica, por un lado, un proceso común con el devenir y las características de otros establecimientos nacionales y, por otro, la particularidad regional que significa la construcción de un origen vinculado a las campañas militares contra los indígenas.

El análisis de los museos de frontera puede dar cuenta de los procesos por los cuales ciertos episodios otrora fueron celebrados y en la actualidad, de manera gradual pero en crecimiento, son catalogados como genocidas $y$, por ende, de las tensiones que emergen entre ambas interpretaciones.

Con este trabajo, intentamos contribuir al estudio de aquellos discursos hegemónicos, cristalizados en el imaginario de los argentinos, como la extinción del indígena pensado como actor social del pasado y caracterizado como salvaje, bárbaro y/o extranjero y en el rol de los museos de frontera en legitimar o refutar dichas nociones.

\section{Caracterización y origen de los museos de frontera}

El origen de muchos museos del mundo, incluyendo a los establecimientos de la última frontera bonaerense, está vinculado a una colección privada que pasa a la esfera

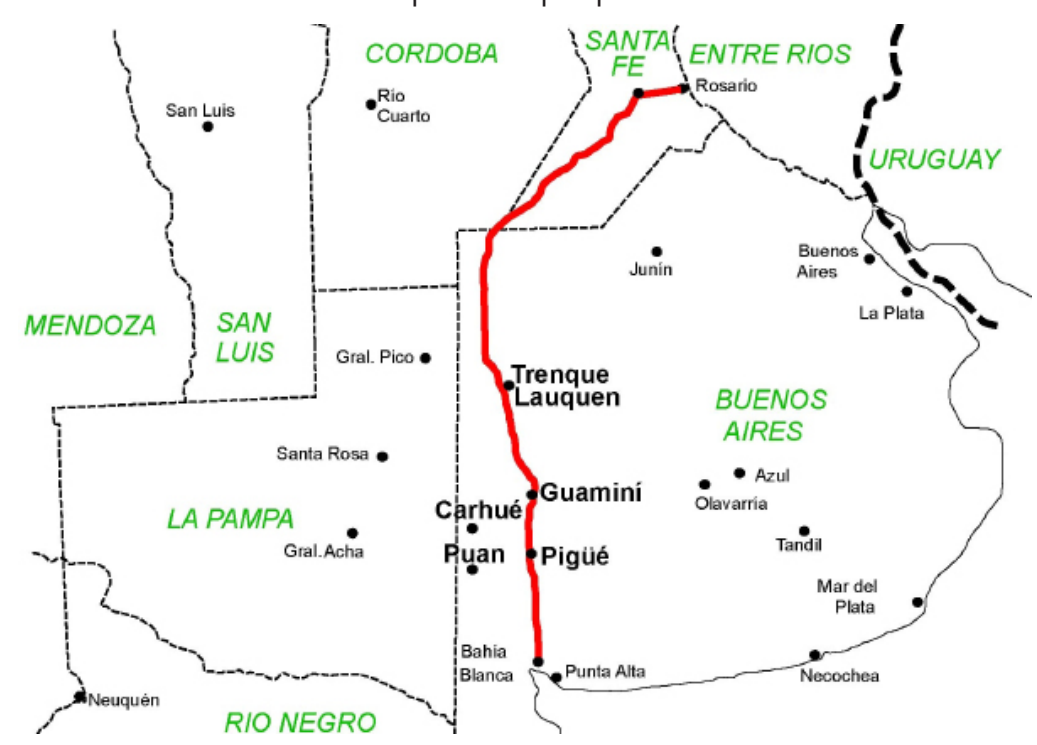

Figura 1. Ubicacón relativa de la Zanja de Alsina

Figure 1. Relative location of Alsina's Ditch estatal. Este pasaje contiene:

"un acto de violencia estatal: la conquista de un territorio, la dominación de un grupo, la muerte de los individuos vivos, la internalización por coerción o consenso de determinadas reglas sociales. Y, en verdad, la relación entre las colecciones y las guerras de conquista ha sido una constante en la trayectoria de los museos" (Podgorny 2005:232233; Podgorny-Lopes 2008:12).

Dicha premisa se ajusta al caso de los museos de frontera dado que sus colecciones están mayormente compuestas por los objetos y vestigios encontrados por particulares en lo que fueran los campos de batalla contra el indio. Autodenominados como museos históricos, seguimos a Blasco en su definición como:

“instituciones dedicadas a la recolección, conservación y exhibición pública de piezas, documentos y objetos materiales del pasado que proponen una perspectiva cronológica para ilustrar un determinado proceso histórico generalmente asociado a la construcción identitaria y que de modos diversos [...] construyen un 'relato' del pasado que hace 'olvidar' determinadas imágenes y 'realzan' otras con una finalidad determinada" (Blasco 2007:1).

Los museos aquí analizados comparten además una cronología en común. A partir de su tardía conformación, los museos de la última frontera no pueden ser contextualizados siguiendo las etapas de creación sistemática de museos a nivel nacional iniciada con la organización estatal de fines del siglo XIX, entre otros el Museo de La Plata (1888) y el Museo Histórico Nacional (1891) fundados en ese entonces (Pupio 2005, Farro 2009).

En la década de 1940 existían casi treinta museos históricos y dieciocho de éstos se habían originado después de 1935 en el marco de una intensa disputa pública, en la cual el estado buscaba prevalecer en acciones orientadas a institucionalizar la actividad historiográfica y conformar un relato histórico oficialmente consagrado (Blasco 2007:18).

A su vez, la reforma constitucional de 1949 creó organismos para la promoción, creación y centralización de los establecimientos (Pupio 2005) y fomentó un contexto institucional que impulsó el traspaso a la esfera pública de las colecciones que algunos personajes de cada localidad venían recolectando como pasatiempo. En ese contexto surgieron museos que como particularidad tuvieron a aquellos dueños 
de las colecciones como sus primeros directores.

Este aspecto no es un detalle menor en el proceso de creación de los museos municipales, dada la importancia que aquellas personas le otorgaban a los materiales reunidos y el deber cívico que sentían con la comunidad. De modo que la institucionalización de las colecciones en un recinto público formaba parte de un procedimiento percibido como un acto de desprendimiento de estos ciudadanos, expresando la fuerza del relato histórico fundacional como discurso hegemónico. Esto fue muy valorado en las distintas localidades y destacado sobremanera en la construcción de la historia regional y la de los propios museos de frontera.

Veremos este tipo de procesos en dos ciudades surgidas como comandancias militares en 1876: Trenque Lauquen que cuenta con dos museos, el de la Comandancia y el Histórico Regional "Luis Scalese" y Puán y su Museo Ignacio Balvidares.

Para ello se han relevado las colecciones de dichas instituciones, atendiendo especialmente a la disposición de las salas, la organización de las exhibiciones y los relatos que se ofrecen en la cartelería e indicaciones. Lamentablemente, ninguno de los museos ${ }^{1}$ cuenta con publicaciones impresas de difusión de las actividades de los establecimientos o referidas a hechos históricos regionales que pudieran enriquecer el enfoque.

\section{Trenque Lauquen, ciudad emblema de la Conquista del Desierto}

Por diversos motivos Trenque Lauquen representa el caso más significativo en torno a la Conquista del Desierto. En primer lugar porque se trata de la única ciudad de la última frontera que posee dos establecimientos referidos al avance estatal y a las campañas militares, el Museo de la Comandancia y el Museo Histórico Regional Luís Scalese. En segundo término, porque solo allí ha logrado conservarse la construcción de la comandancia militar que dio origen al pueblo en 1876, sitio declarado Monumento Histórico Nacional en 1953 y organizado como museo tras subsistir durante varias décadas desempeñando distintas funciones. En tercer lugar, porque es en Trenque Lauquen en donde más se ha celebrado y reflexionado sobre la Conquista del Desierto, lo que llevó en 1965 a impulsar la Semana Nacional de la Conquista del Desierto, evento que tuvo lugar hasta tiempos recientes (Nagy 2008).

Finalmente, y como punto nodal para este trabajo referido a los relatos sobre los pueblos indígenas, es la única ciudad de la ex zanja de Alsina (1876) que cuenta

\footnotetext{
1 Cabe destacar que en 2006 los museos de las otras dos comandancias militares fundadas en 1876, Carhué y Guaminí, comenzaron a publicar una revista de historia regional denominada Museos del Desierto. En la actualidad lleva once números y los temas refieren a semblanzas de personajes locales ilustres, a efemérides de sucesos importantes (la llegada del ferrocarril) y a recordatorios de instituciones emblemáticas de la región como escuelas, bancos, etc.
}

con una comunidad indígena organizada, la Cacique Pincén. De modo que los museos y la historia del lugar están expuestos a una mirada crítica que cuestiona las construcciones hegemónicas que han invisibilizado la presencia de estos pueblos. Desde un tiempo a esta parte, es en Trenque Lauquen donde las narrativas tradicionales hegemónicas están puestas en debate permanentemente, situación que no se da con la misma profundidad y complejidad en otras comandancias de la ex frontera devenidas ciudades (Puan, Guaminí y Carhué).

La sola presencia de la comunidad indígena y su reconocimiento conlleva un discurso crítico implícito, en función de que el relato hegemónico los ha eyectado de la historia, de modo que su agencia y su articulación comunitaria obliga a revisar el paradigma tradicional que avalaba su extinción.

Como se ha mencionado, Trenque Lauquen posee dos museos históricos y ambos vinculados a las campañas militares. El más importante fue rebautizado recientemente como Museo Histórico Regional Don Luís Scalese, abandonando el nombre de "Museo Histórico de las Campañas al Desierto General Conrado Villegas" que llevaba desde 1951 cuando había pasado a formar parte del ámbito provincial.

El otro establecimiento, no siempre fue museo y es la original comandancia original fundada en 1876. Cubierta por un templete, forma parte del mismo edificio que pertenece a la municipalidad y fue reorganizado en 2008 como Museo de la Comandancia en los actos por el 132 aniversario de la ciudad recreando, según Juan José Estévez, el entonces Coordinador de Museos de Trenque Lauquen, su antigua fisonomía y disposición del amoblamiento:

"...Cuál fue el simbolismo que le dimos, porque (antes de 2008) todo el acervo estaba adentro de la comandancia y ahora la comandancia es la sala príncipe y todo el acervo está en el templete, le dimos a la comandancia la ambientación que nos lleva a pensar cuando ingresamos, que Villegas se fue hace cinco minutos..."2

Entre los museos de frontera, el pionero fue Luís Scalese, quien en 1944 impulsó la fundación del Museo Histórico Regional de la Conquista del Desierto, denominación que conservaría hasta el mencionado traspaso a la provincia, en 1951. Scalese era un reconocido "autodidacta y aficionado de la cultura, un navegante solitario" tal la definición de sus propios familiares (Semadeni 2010: 224).

Durante varios años las salas funcionaron en su propiedad y exhibían diversos objetos recogidos en recorridas por los campos llevadas a cabo durante sus tiempos libres. Claramente, adscribe al "museo de padre único" que

\footnotetext{
2 Juan José Estévez, ex Coordinador de Museos de Trenque Lauquen. Entrevista personal, febrero 2009.
} 
Pupio (2005) toma de Rosso (1991), es decir "museos pequeños e íntimos, situados generalmente lejos de las grandes ciudades y que a menudo tienen su origen en una sola persona" (Rosso, en Pupio op. cit: 208). Éstos surgen por la donación de colecciones de quienes, dado su prestigio local, se convierten en supervisores y directores de los incipientes establecimientos.

No exento por ello de las penurias económicas, fruto de la no asignación de presupuesto y de no formar parte de las políticas municipales primero y provinciales después, el museo funcionó durante dos décadas en la casa de Scalese, para luego iniciar un derrotero por distintos lugares. En 1963 fue trasladado a las instalaciones del Tiro Federal, sin embargo apenas cuatro años después, en 1967, abrió sus puertas en la casa particular de Almafuerte $^{3}$, hasta que finalmente, en 1970, fue abierto en el parque municipal a partir de una inversión proveniente de la provincia, que había sido anunciada por los funcionarios en 1959 pero que fue dilatándose varios años. En 1980 a través de un convenio, el museo se municipalizó y en 2002 recibió en su biblioteca al Archivo Histórico Municipal. La última remodelación en cuanto al recorrido data de 2004, cuando se intentó generar un "circuito más fluido y dinámico"4.

En la actualidad se encuentra en el parque municipal junto a la reproducción de un fortín y sus colecciones han sido revisadas, presentando una enorme fachada compuesta por 28 murales del artista local Rodolfo Campodónico. Además fue rebautizado con el nombre de su impulsor, Luís Scalese, entre otros motivos porque la antigua denominación era celebratoria de las campañas militares.

Este cambio ocurrido en 2011 representa un ejemplo de las contradicciones y las distintas miradas existentes acerca de la propia historia local, de cómo distintos actos, instituciones o personas están enraizadas en un cierto modo de apreciar el origen y la comunidad de Trenque Lauquen y lo complejo que resulta modificar determinados preceptos. El cambio de la denominación partió desde la Dirección de Museos, con el objetivo de homenajear a Luís Scalese, impulsor del establecimiento y dejar de lado el antiguo nombre de perfil militarista "Museo de las Campañas al Desierto, General Conrado Villegas". En dicho homenaje al fundador (Scalese) implícitamente, al mismo tiempo, se desechó la visión que el propio homenajeado poseía acerca de la Conquista del Desierto y los motivos que lo llevaron a fomentar tal emprendimiento.

Al menos desde el nuevo nombre, es aceptable pensar que se trata de un hecho simbólico que rescata la

\footnotetext{
3 Almafuerte fue el seudónimo utilizado por Pedro Palacios, poeta nacido en 1854, en San Justo, provincia de Buenos Aires. En la década de 1890 se radicó en Trenque Lauquen. En 1973 su vivienda fue declarada Monumento Histórico Provincial y se convirtió en museo.

4 Tríptico del Museo Histórico exhibido en la cartelera del Museo de la Comandancia.
}

abnegación y el sacrificio de Scalese por dotar a Trenque Lauquen de un lugar donde se alojaran las colecciones y objetos que narran la historia de la región. Sin embargo, a priori, el reemplazo no sólo refiere a la denominación que se impuso, sino también a la que se buscó descartar, de modo que es factible asegurar que el rescate de Scalese es por su obra y no por sus interpretaciones. El análisis de las salas y sus exhibiciones permitirán concluir si la actual organización del museo acompaña el cambio de perspectiva que la Dirección de Museos ha llevado adelante.

\section{Un recorrido por el Museo Regional Luís Scalese}

Indudablemente, el actual Museo Histórico Regional de Trenque Lauquen tuvo en su origen y desarrollo una fuerte vinculación con el relato de las campañas militares, tal su nombre desde la fecha de fundación en 1944 hasta el reciente cambio de denominación. La impronta de haber nacido y crecido como una institución abocada a un tema específico resulta evidente al recorrerlo, pese a que en los últimos años se ha propugnado convertirlo en un establecimiento dedicado a la historia en general y no sólo al surgimiento de Trenque Lauquen en el contexto del avance de las fronteras.

La institución es señalada como un espacio de referencia o ejemplo a seguir por directores de museos o funcionarios de cultura de otras localidades de la última frontera ${ }^{5}$. Esto obedece tanto a su tamaño como a lo profuso de sus colecciones. Dividido en siete salas no todas señalizadas, cuenta con dos espaciosas habitaciones dedicadas, una al avance de Adolfo Alsina de 1876 y otra abocada a Roca y a la Conquista del Desierto (1879-1885).

Apenas se ingresa, se manifiesta en el modo de catalogar y de reorganizar las secciones y en lo expresado por los responsables del museo, la intención de aggiornar el discurso que el establecimiento venía difundiendo y reproduciendo. En la misma arcada, que divide el Hall Central de la "Sala de la Prehistoria", se ha pintado un quepi de los oficiales y una guarda pampa. Subyace una idea que busca equiparar la situación de blancos con indígenas evidenciada en la elección de la frase de Nicolás Levalle, coronel de las campaña y comandante de una de las cinco divisiones: "No tenemos yerba ni tabaco ni ropa, ni recursos, ni esperanzas de recibirlos...! Estamos en la última miseria, pero tenemos deberes que cumplir...!".

De este modo, soldados e indios debieron sufrir las mismas penurias, en una naturalización y particularización del proceso histórico (Alonso 1988) que presenta a los acontecimientos como parte de una tragedia y una injusticia inevitable, que borra responsables y

\footnotetext{
${ }^{5}$ Eduardo Hiriart encargado del Museo Marcelino Freyre de Guaminí e Iván Partarrieu, Director del museo Dr. Adolfo Alsina de Carhué, señalaban ciertas limitaciones para su crecimiento y desarrollo y marcaban que las instituciones que ellos dirigen no cuentan con tantos recursos y espacios "como en Trenque Lauquen". Comunicaciones personales con Eduardo Hiriart e Iván Partarrieu. Febrero 2010.
} 
beneficiarios, pero que es compartida por actores sociales que sufren las mismas consecuencias, pese a ocupar roles absolutamente diferentes en los hechos.

Esto se refuerza en una de las dos novedades que ha impulsado la coordinación de los establecimientos: la sala de la Prehistoria (la otra es la reorganización de la sala $\mathrm{N}^{\circ} 3$ ). Con la renovación, el museo ofrece un claro relato evolutivo que comienza en el origen del planeta, con extensa y abundante cartelería que brinda detalles acerca de las distintas eras y presenta restos fósiles o reproducciones de los primeros mamíferos. Es de destacar que en la misma sala se exhiben morteros, puntas de flecha, boleadoras y la única vasija entera encontrada en la provincia de Buenos Aires ${ }^{6}$. No hay mención alguna a la antigüedad de las piezas, de modo que la utilización del término prehistoria parece sugerir que recibe dicho calificativo debido a que pertenecía a sociedades indígenas.

El recorrido continúa por la "Sala Aborigen" dispuesta entre las nuevas salas "De la Prehistoria" y "No 3", esta última dividida en tres recintos: A) Etapa colonial, B) Etapa federal y C) Etapa rurales. Se rompe así con la propia línea cronológica propuesta por el museo, con el agregado de que las muestras refieren mayormente al siglo XIX y sólo algunas al período tardo colonial. La colección es sumamente ecléctica y contiene desde fotos de indios del Chaco hasta pobladores originarios que vivieron en la ciudad. Hay objetos diversos, como ponchos, rosas de los vientos, indicaciones que resaltan la importancia del caballo, instrumentos y utensilios y las célebres fotos de Pincén tomadas por el fotógrafo Antonio Pozzo en 1878, acompañada de una señalización que explica su captura y su posterior confinamiento, bautismo y casamiento en la isla Martín García. Es importante remarcar que Juan José Estévez además de ejercer como coordinador de museos hasta 2011, fue autor de la biografía más exhaustiva sobre el cacique (Estévez 2011).

Estos datos no han repercutido de forma significativa en la concepción y organización de las colecciones referidas a los pueblos originarios, dado que muchas de sus aseveraciones están basadas en investigaciones muy antiguas (Casamiquela 1969), manifestadas en vitrinas o croquis que dan cuenta del "avance de la araucanización" y el "Panorama etnológico de Pampa y Patagonia", desde propuestas cuestionadas desde hace tiempo por distintas líneas de investigación (Mandrini-Ortelli 1995, LazzariLenton 2000, Moyano 2007 ).

El conjunto sin orden aparente y heterogéneo de la "Sala Aborigen" poco contribuye a esclarecer las formas de vida de los pueblos indígenas de la región antes de

\footnotetext{
6 La vasija de "Huitru Loo" fue hallada en la década del '50 en cercanías del establecimiento rural "Nueva Castilla", partido de Trenque Lauquen, estaba en guarda del Museo de Ciencias de La Plata y fue cedida en 2008 al Museo de Trenque Lauquen. Ver en http://www. trenquelauquen.gov.ar/gacetillas/22-12-08.pdf
}

las campañas y menos sugiere acerca de las políticas genocidas aplicadas por las autoridades militares para su sometimiento, confinamiento y posterior distribución (Delrio 2005, Lenton 2005, Papazian y Nagy 2009). La incorporación de dos breves historias de vida aparece como detalle o hecho anecdótico excepcional y no establece relación alguna con los actuales habitantes de la ciudad. Existe entonces un alineamiento consistente con el supuesto hegemónico de extinción del indígena, que al mismo tiempo establece los márgenes para la supervivencia en la figura estereotipada de los descendientes. Esta funciona como la metáfora de una llama que se fue extinguiendo indefectiblemente, en una operación que produce una remisión discursiva al pasado y una arqueologización conceptual de los indígenas (Navarro Floria 2007:42).

Una paradoja marca el momento actual del museo, ya que pese a la creciente visibilidad que la agencia indígena va ganando en Trenque Lauquen, no obstante se trata de una sala Aborigen que proclama su extinción y su pertenencia a un estadio anterior y pasado. La contradicción se hace presente en ciertos eventos, como cuando en 2009 se inauguró un nuevo sector en el museo, con la exhibición de la mencionada vasija de Huitru Loo, en el cual las autoridades del museo invitaron a los miembros de la Cacique Pincén.

La cartelería de los objetos y la información brindada acerca de los pueblos originarios se tornan insostenibles ante la comunidad indígena, que con su sola presencia cuestiona los presupuestos de la colección y evidencian que sus trayectorias e historias han quedado afuera de los relatos tradicionales del museo y de la ciudad de Trenque Lauquen.

El siguiente espacio lleva la denominación "Sala de la Colonia", aunque en el plano ésta integre la "Sala No 3 " dividida en las tres etapas ya consignadas. En el mismo cartel indicativo se incorporó un texto que no refiere el autor pero si menciona la pérdida de la independencia indígena y vuelca una particular visión de la historia:

“...esa lucha en estas extensas llanuras que fueron el escenario donde dos razas fuertes y generosas no se comprendieron, pero se respetaron, no se amaron pero se temieron con la grandeza indómita de los héroes".

Esta interpretación de "respeto mutuo" y una aparente "amistad" entre quienes en realidad fueron acérrimos enemigos, puede comprenderse en el contexto de la operación histórica que se realizó en la ciudad incorporando la figura del cacique Pincén junto con la del único y venerado prócer fundador, el General Conrado Villegas. La entronización de Pincén logra matizar el perfil militarista y celebratorio de la Conquista del Desierto que la ciudad poseía, al resaltar un respeto mutuo entre el indígena y Villegas, basado en las conversaciones 
sostenidas cuando Pincén fue apresado y en el intercambio epistolar mantenido cuando fue confinado en la isla Martín García. Esta interpretación, elude el contexto general de avance de las tropas y el sometimiento de los pueblos indígenas y soslaya una cuestión particular de la relación entre ambos, el apresamiento del cacique y su condición de sometido respecto a su interlocutor.

Las habitaciones reservadas para los sucesos de las campañas militares son las más espaciosas en concordancia al origen y al nombre del museo. Divididas cronológicamente, de acuerdo a sus desempeños frente al Ministerio de Guerra, una se denomina "Sala Dr. Adolfo Alsina" y la otra "Sala del General Julio A. Roca". En la primera de ellas, además de frases, cuadros, la mascarilla mortuoria de Alsina, restos de uniformes, como botones, espuelas y armas, nuevamente, en un cartel referido al corrimiento de la frontera de Alsina (1876), se coloca al indígena como actor social del pasado: "El médano, lugar que habitó el indio en su vida nómade hoy es el yacimiento arqueológico donde se encuentran los instrumentos líticos que dan testimonio de su cultura".

Desde esta concepción, para el abordaje de la cultura indígena deben rastrillarse los médanos, pero no se contempla la posibilidad de escuchar los testimonios y dialogar con los miembros de la comunidad Cacique Pincén. Aparentemente, las piedras tienen más para decir que las personas respecto a las sociedades indígenas. Más allá de la ironía, predomina un interés por el pasado arqueológico y remoto indígena, inmanente, cómodo de abordar y acrítico respecto a las relaciones sociales actuales, mientras el análisis de la historia reciente puede conllevar a serios cuestionamientos respecto a la historia oficial de Trenque Lauquen.

Como se ha mencionado, la habitación más completa es la que aborda la Conquista del Desierto, denominada "Sala del General Julio A. Roca". Reúne distintos objetos de las campañas, en especial armas, retratos y libretas de militares expedicionarios, quepis, uniformes, monturas, carruajes e instrumentos de mensura y medición que cargaban los ingenieros que acompañaban las tropas. El lugar resalta por la cantidad de armamento y pertrechos para los combates, que según la cartelería fueron encontrados en distintos "campamentos de la zona".

En esta sala hay también una maqueta de la comandancia, biografías de "expedicionarios del desierto" y de los ingenieros, algunas de ellas acompañadas con fotos, gran variedad de objetos personales como monedas, cigarreras, medallas conmemorativas, proyectores y cámaras fotográficas; un croquis del campamento levantado en 1876 y una reproducción del cuadro de Blanes, obra infaltable a la hora de consolidar e ilustrar el acontecimiento Conquista del Desierto.

La particularidad del Museo Histórico Regional es que debajo de la pintura hay un croquis que establece un número para cada una de las personas que aparecen en el óleo, que junto a la consignación del año (1879), intenta transmitir la idea de que se trató de un hecho realmente sucedido en esa fecha, aunque la obra reúne a personajes que nunca estuvieron juntos en las campañas militares y surgió a solicitud de Carlos Pellegrini en 1889, con motivo del décimo aniversario del inicio de las campañas (Pinto Aparicio 2005).

En este punto del trayecto, el visitante ya ha pasado por la sala de la Prehistoria, Aborigen, y la $N^{\circ} 3$, lugares que encierran grandes períodos y también por las importantes habitaciones dedicadas a Alsina y a Roca que, comparativamente, refieren a un breve lapso y a una temática específica. Como se ha dicho, esto se sustenta por el origen y la propia denominación que el museo llevó a lo largo de su existencia.

La importancia otorgada a las campañas militares como procesos que propiciaron el origen de la ciudad requiere sin embargo incorporar a un personaje que pueda recibir pleitesía y homenajes locales, sin ser compartido con otras localidades surgidas en las mismas circunstancias. Es decir, Alsina y Roca, ministros de guerra de las campañas, devinieron héroes de una gesta de alcance nacional que si bien incorpora a los sucesos de fundación de Trenque Lauquen, no posibilita narrar una historia propia. Para ello es necesario potenciar la figura de un prócer, de un fundador, rol que cumple la "Sala del General Conrado Villegas", militar que comandaba la avanzada que arribó al paraje que albergaría el fortín, la comandancia y luego la ciudad.

Es por ello que el relato hegemónico del lugar y del museo se completa con la sala dedicada al fundador. Un espacio que alberga cartografía acerca de las campañas, una serie de retratos de su persona en distintas etapas de su vida, una transcripción de una carta de 1883 escrita por Roca con palabras elogiosas hacia Villegas, un enorme panel titulado "Gral. Conrado Villegas El Fundador" con cuadros de él y su esposa Carmen Granada, adornado con su lanza y sus espuelas y estandartes con sendas banderas de Argentina y Uruguay, este último, país de origen del militar. La procedencia extranjera del prócer no lo torna incompatible con el mito de fundación y pertenencia, condición que sí será presupuesta y señalada como aspecto deslegitimador al momento de abordar determinados reclamos de la comunidad indígena Cacique Pincén. Se exhibe también una serie de cartas que Villegas escribió y recibió de su mujer y de Pincén, crónicas que narran el fallecimiento del militar, sus funerales y listados con los primeros pobladores de la localidad.

La sala dedicada al fundador posee además un material que brinda un manto legitimador al relato propuesto por la historia tradicional de la ciudad. Se trata de una crónica escrita por José Francisco Mayo, pionero historiador local y autor de la biografía de Villegas (Mayo 2003). En el escrito, titulado "Nace un pueblo", Mayo narra 
las primeras decisiones tomadas por el general para la fundación de Trenque Lauquen:

\begin{abstract}
"En la misma tarde del 12 de abril, en cumplimiento de órdenes recibidas, Villegas con su escolta marchó hacia Las Tunas para reconocer el paraje; pero la falta de agua le hace preferir Trenque Lauquen para establecer la Comandancia de la Frontera Norte. El 15 de abril levanta un mangrullo de siete metros de alto sobre el médano más elevado de los que rodean la laguna, estando situado en lo que es hoy el boulevard Villegas. Se inician operaciones de exploración, se recorre la zona asignada cuidadosamente y simultáneamente en cumplimiento del pensamiento civilizador de Alsina, el 27 de abril, se inicia el trazado y delineación del pueblo..."
\end{abstract}

Nótese que el texto muestra por los menos dos valores insoslayables de Villegas que merecen ser homenajeados. Por un lado la obediencia entendida como acto de nobleza y transparencia, en función de que se está llevando a cabo un plan "civilizador". Así, el general pronto se apresta, "según órdenes recibidas", a recorrer Las Tunas donde se había programado fundar la comandancia. Días después explora la zona y "en simultaneo con el pensamiento de Alsina" traza y delinea Trenque Lauquen. Pero como con la obediencia no alcanza para ser erigido como prócer, un inteligente Villegas entiende que el lugar previamente pensado para emplazar el pueblo, Las Tunas, no ofrece las condiciones requeridas por la escasez de agua y toma una decisión que a posteriori significaría un verdadero acto de fundación: Cambiar el plan original e iniciar las tareas de construcción de la comandancia, el mangrullo y por supuesto, el pueblo de Trenque Lauquen.

Villegas deviene así, en un Titán del desierto que logra vencer al indómito cacique Pincén pero se muestra magnánimo en la victoria y hasta se lo señala como respetuoso y amigo del lonko venido en desgracia. Previamente procede ateniéndose con profesionalismo y templanza al plan concebido por Adolfo Alsina, sigue a paso firme y en los tiempos establecidos, las premisas ideadas por el Ministro de Guerra, pero se termina consagrando como El fundador cuando con sapiencia y determinación toma la decisión de salirse de la idea original y establecer el campamento en Trenque Lauquen.

El recorrido por el museo se cierra con un pequeño recinto, la "Sala de los Primeros Pobladores", un lugar que reúne una colección de distintos objetos antiguos. Algunas de las paredes cuentan con puertas que comunican con las otras salas, pero que se encuentran cerradas con rejas, con el objetivo de demarcar un recorrido determinado por la evolución cronológica dispuesta para el museo.

Esta invitación obligada a recorrer el establecimiento desde un pasado arqueológico hacia el presente no sólo forma parte de una organización del espacio sino también un modo de interpretar la historia y sostener un discurso hegemónico. Como ha señalado Delrio siguiendo a Andermann, en la actualidad los museos "se vieron obligados" o son proclives a exhibir objetos indígenas como parte de una historia científica de la ancestralidad de la nación argentina (Delrio 2008: 4). De modo que personas (indígenas) contemporáneas están expuestas y construidas como pasado, en piezas patrimoniales del museo, al mismo tiempo que son explicadas (ellas y la afirmación de su extinción) como parte de una lógica de evolución, como piezas del patrimonio de una historia natural.

En el caso del Museo Luís Scalese, se parte de los gliptodontes, los morteros y las puntas de flecha; de la cartelería que explica la vida "hace 4600 millones de años" y ubica los asentamientos prehistóricos de Trenque Lauquen, junto a vasijas y objetos encontrados miles de años después, espacio en el que también pueden verse reproducciones de un toldo de un cazador recolector y su lanza. En la sala contigua, pueden apreciarse fotos de algunos indígenas, como Martina Pincén, quien ha fallecido en la década de 1970. Sin embargo, como se ha explicado, temporalmente la sala indígena es anterior a la sala de la Colonia.

\section{El Museo de la Comandancia}

Existen rasgos compartidos entre el Museo Histórico Regional y el de la Comandancia. Además de diversos objetos similares en torno a las campañas militares, como croquis de las fronteras, reproducciones pictográficas y restos de uniformes y armas, las novedades tienen que ver con la reproducción de la primera subcomisaría que funcionó en la ciudad a comienzos de 1880, un cañón de guerra, diversas placas metálicas alegóricas a los aniversarios de Trenque Lauquen provenientes de distintas organizaciones y ciudades del país y, sin duda alguna, el flamante busto de Pincén que en reemplazo del de Roca que allí estaba situado, acompaña desde el 2009 al que ya existía de Conrado Villegas.

La eliminación de la escultura de Roca, tuvo que ver con que Trenque Lauquen surgió en el marco del avance de Alsina en 1876 y, según afirman las autoridades de la Dirección de Cultura, poca es la relación del ideólogo de la Conquista del Desierto con la historia de la ciudad y menos con el de la comandancia. Su reemplazo por la figura del Cacique, en gran medida obedece al impulso de Juan José Estévez, el ex coordinador de museos:

"... Retiramos el busto de Roca, lo hicimos como explicación que dimos desde lo histórico, no se corresponde con la época del avance de Alsina, en 1876 Roca históricamente no ha sido del agrado del sentimiento popular de los trenquelauquenses, que en todo caso tienen una admiración y respeto por el fundador (Villegas) quien tuvo impresiones de elogio hacia el cacique Pincén, los dos se retribuyeron 
elogios y hay documentos que lo comprueban. Entonces me parecía que si había dos pilastras para elevar como homenaje a esas dos personas, eran nuestras dos máximas figuras históricas, que eran Pincén y Villegas. No soy partidario de ocultar la historia. Roca tiene su lugar en el Museo Histórico, en el Conrado E. Villegas (Hoy Scalese), allí hay un cuadro muy importante, los efectos personales y no se lo retiró de otros lugares, pero sí del museo de la comandancia"7

Así las cosas, de un tiempo a esta parte los museos de Trenque Lauquen han encarado una serie de reformas acerca de sus colecciones y de los relatos que ellas ofrecen. Iniciada hace algunos años, dicha interpretación ha incorporado a Pincén al panteón de los próceres de la ciudad pero no le otorga interés alguno a la historia de la propia comunidad indígena que allí reside.

Esto obedece a un posicionamiento hegemónico que permite recuperar la cultura ancestral en algunos aspectos simbólicos pero que no está dispuesto a ingresar a un campo de lucha donde lo material, específicamente el acceso a la tierra, se fije como agenda. De modo que la elevación del cacique Pincén, rendirle homenaje y contar su historia remarcando su supuesta relación amistosa con Villegas, coloca a Trenque Lauquen como una comunidad respetuosa de la diversidad.

Principalmente, el retiro de la imagen de Roca implica una reafirmación de la identidad particular local, en un contexto de cuestionamiento generalizado a la historia hegemónica que la figura del ex-presidente evoca como ícono.

Sin embargo la incorporación de Pincén no implica necesariamente un cambio de paradigma en tanto no son incorporadas otras trayectorias sociales que hacen al proceso regional y local. Abordar la historia de la comunidad indígena, incorporar su devenir y sus trayectorias, sus relatos de la Conquista dotarían al museo de una versión distinta de la historia de la ciudad y del país. Sin embargo, seguir esa línea significaría adoptar un posicionamiento incómodo que disputara ciertos conceptos e ideas arraigadas en el seno de la sociedad. Por tanto, genera menos conflictos incorporar otra figura como la del lonko, soslayar determinados episodios (sometimiento, campos de concentración, distribución de indígenas) ${ }^{8}$ y resaltar otros (la "amistad" entre el fundador Villegas y el derrotado Cacique).

\footnotetext{
7 Juan José Estévez 2009. Entrevista personal.

${ }^{8}$ En la historia tradicional de Trenque Lauquen y de la Argentina, Martín García era un lugar de confinamiento y circulaba la idea de que allí fueron recluidos los indígenas sometidos en la Conquista del Desierto. En los últimos tiempos, algunos trabajos (Mases 2002, Delrio 2005, Lenton 2005, Papazian y Nagy 2009) han profundizado en esa línea y, con matices, han caracterizado a la isla como un campo de concentración. La biografía de Estévez (2011) ocupa un capítulo sobre los días del cacique Pincén en Martín García, pero no hay un análisis o intento de entender el confinamiento en el marco de una política estatal.
}

El rol del museo regional en esta reconstrucción histórica es vital. En él se exhiben "pruebas" de la relación entre el militar y Pincén y en todo caso, al momento de mencionar a los indígenas como comunidad, con sus prácticas, conviene ir a los médanos, recoger piedras y vestigios de tiempos remotos, para profundizar en el poblamiento de la región y en las prácticas de pueblos ya extinguidos.

Si la agencia indígena reclama estar viva, en movimiento y luchando, el museo puede invitarlos como público al evento donde se exhibe una vasija de tiempos inmemoriales. Y si además visitan la sala referida a las sociedades originarias, podrán comprobar como la misma institución que los ha convocado, sostiene en distintas colecciones, que ellos forman parte del pasado, y por tanto, ya no existen.

\section{Puan y su Museo}

El surgimiento del museo de Puan es posterior al de Trenque Lauquen (1944) y adscribe al modelo de "padre único" (Pupio 2005) que hemos descripto. Sin embargo, a diferencia de cómo suele ocurrir en el origen de estas instituciones, su promotor no ofició de director cuando, a partir de sus donaciones, el museo finalmente abrió sus puertas en 1973. Esto obedeció a que Don Ignacio Balvidares era un hombre de avanzada edad cuando impulsó la conformación del museo entre fines de la década de 1960 y comienzos de 1970. Para aquel entonces, Balvidares rondaba los ochenta años, residía en Bordenave, a unos 40 kilómetros de la ciudad cabecera de Puan y finalmente fallecería en 1973, poco antes de que su colección se trasladara y se inaugurara el museo que lleva su nombre.

Según la propia información del Museo, la idea de la donación para armar un museo local habría surgido en 1969, cuando a partir del deseo de Balvidares, se constituyó una comisión del Museo Regional de Puan dirigida por su amigo Carlos Castello Luro, a posteriori el primer director del establecimiento.

La colección que Balvidares delegaría al municipio se encontraba expuesta en un museo privado organizado en su campo, "El Ñacurutú", ubicado en las proximidades de Bordenave. No obstante, pese a su fallecimiento, su familia cumplió con lo acordado y en diciembre de 1973, un recinto del Palacio Municipal comenzó a funcionar como Museo.

Sin embargo, la primera etapa de vida resultó breve ya que la irrupción de la dictadura militar provocó que se encajonaran los objetos hasta 1984. Con la democracia, se consiguió su reapertura provisoria en la Sociedad Española, hasta que en 1991 el Museo Ignacio Balvidares fue trasladado al Mercado Municipal, su sede actual desde hace dos décadas.

Para 2008, en el marco de su aniversario número 35, 
las autoridades calculaban que el museo había recibido más de 50.000 visitantes, se habían realizado más de 40 talleres, alrededor de 190 muestras e impulsado unos 300 relevamientos ${ }^{9}$.

\section{Un recorrido por el Ignacio Balvidares}

Una primera mirada permite percibir que el museo está integrado a la Dirección de Cultura de Puan, muy bien cuidado, prolijo y con referencias claras. De menor tamaño que el establecimiento de Trenque Lauquen, sin embargo posee una importante cantidad de material ordenada de tal modo que no resulta complejo comprender el criterio de organización que se ha adoptado.

Ubicado en la esquina de una de las calles principales de la ciudad, San Martín, hay placas en sus paredes exteriores y algunos pocos objetos que, por su tamaño, se exhiben por fuera del edificio, como el cañón encontrado en las cercanías de la Zanja de Alsina. El museo cuenta con cuatro salas temáticas que no siguen un orden cronológico.

Al entrar se encuentra el lugar más importante, la sala "Evolución de un Pueblo", un recinto de forma rectangular recargado de objetos y referencias varias. Lo primero que se observa al ingresar es una pared convexa con un dibujo de un indígena oteando el horizonte, desde donde proviene una tropilla de caballos con jinetes. En la parte superior del muro se acompaña el gráfico con una frase del historiador local César Michelutti: "Tierra de nómades, indios, campamento militar, pueblito de frontera; voy a adentrarme en tu pasado". A la derecha, aún tapado el resto del salón por el obstáculo visual que presenta el muro mencionado, aparece un retrato y una vitrina con objetos personales de Ignacio Balvidares. En esa misma pared cuelga un croquis de la última frontera con la inscripción "La estrategia de frenar al indio por el Dr. Alsina-1876".

Superado ese espacio, se expone una importante sección compuesta por armas de todo tipo encontradas en la región. También en respectivos recuadros, se exhiben botones y cascos de balas obtenidos en tiempos actuales en trabajos de excavación, una reproducción de la línea de fortines del plano topográfico elaborado por el ingeniero Wisocky y un telegrama de abril de 1877, enviado desde la comandancia de Puan al ministro de Guerra Adolfo Alsina por parte de Nicolás Levalle, en el que se notifica que "los indios de Namuncurá han salido de sus toldos con destino de invadir las fronteras de la provincia, sin determinar a cual".

En el centro de la sala una serie de objetos e imágenes refieren al origen del campamento de Puan, cuya

\footnotetext{
9 Todas las Voces. El diario de Puan. Artículo "35 años cuidando y valorando la historia de Puan. 13/12/2008. En el sitio web http:// www.diariodepuan.com.ar/2008/12/35-anos-cuidando-y-valorandola-historia-de-puan/
}

exhibición se realiza en paneles vidriados con fotos. Dos planos del ingeniero Jordan Wysocki aparecen en la parte cóncava de la pared antes mencionada. Uno General de la Zanja y otro Topográfico correspondiente a la nueva línea de frontera de la Comandancia de Puán, ambos de 1877.

Algunas fotos de Pozzo, de abril de 1879, dan cuenta del paso por Puan de Julio Roca y su comitiva de militares, profesionales y sacerdotes. En la descripción también aparece Pichihuincá, cacique de la "parcialidad amiga" afincada en la misma comandancia, mientras que algunos paneles exhiben croquis del campamento de Puan, comparando la ubicación de las calles actuales con los emplazamientos de las primeras construcciones. En el resto de la sala "Evolución de un pueblo" se exponen diversas estanterías vidriadas que van acompañadas por vitrinas del mismo material, cada una dedicada a una temática distinta y que buscan hilvanar un relato histórico cronológico de Puan.

El recorrido a través de esas estanterías y vitrinas se inicia con "Campamento y origen del pueblo" que exhibe varias fotos de la comitiva de Roca, en 1879. Así pueden verse una imagen panorámica de la Comandancia, la tribu de Pichihuincá y a la propia comitiva posando. Se destaca también un plano de la Sección XIX que anuncia el remate de las tierras que se realizaría en septiembre de 1883 y que en su parte superior indica: "Terrenos cuyo producto ha sido cedido a la nación por la provincia". Allí se ve el ejido de Puán, rodeado de lotes muy grandes ya con los nombres de sus propietarios.

Retomando el recorrido de vitrinas, a la iniciática "Campamento y origen del pueblo" le sigue "Vinieron de lejos... y formaron sus familias" que reúne fotos de familias y listados de personas que aún residen en el pueblo. El primero José Peña, es señalado como de origen indígena. De las restantes se destaca "Nuestros abuelos inmigrantes... trabajadores de sol a sol", que exhibe imágenes de tareas rurales y pretende reforzar la tradición del origen europeo de la ciudad y el esfuerzo de aquellos abuelos inmigrantes que comenzaron a construir al Puan que nacía en aquel entonces.

Cabe señalar que entre cada una de las estanterías también se exhiben objetos, algunos de ellos muy particulares y vinculados a la Zanja de Alsina. Sobresale una réplica de un pico con el cual se cavaba el famoso foso, que se exhibe con un cartel que asegura que solo entre Carhué y Púan se rompieron 1500 picos por la dureza del terreno. Aparecen también herramientas rurales como alambradoras y espanta langostas.

De modo que puede asegurarse que en "Evolución de un pueblo", la principal sala del museo Ignacio Balvidares, más allá de algunos instrumentos y artefactos dedicados a la cultura, predominan las armas y los instrumentos de labranza, expuestos en ese orden cronológico. Aunque, insertada entre las últimas vitrinas, pueda apreciarse 
la colección de "Revólveres de caballería usados por la policía de campaña alrededor de 1885". Como una metáfora de la historia, el mensaje parece transmitir que el origen de Puan fue turbulento debido al asedio indígena, quienes sólo aparecen ocupando un espacio de manera estática y para convalidar su espíritu agresivo y violento que impedía el progreso de la civilización. Como muestra de una actitud general, basta un ejemplo particular, el telegrama enviado por Nicolás Levalle en abril de 1877, cuyo texto afirma el inminente alzamiento y ataque de Namuncurá a la frontera de la provincia, por motivos que se desconocen y sin definir el punto exacto. Se trata del único documento escrito que el museo exhibe, por tanto aumenta su efecto exponencialmente respecto a la caracterización atribuida al indígena: Indómito, agresivo sin justificaciones, aparentemente violento por esencia, aterrador e impredecible. Incluso, el material exhibido como documento no demuestra que haya existido una invasión.

El relato de la sala invita a pensar a las sociedades indígenas en posición de ataque y a los militares y pobladores como seres respetables y civilizados que debieron convivir con el temor a la invasión. No hay ningún tipo de contextualización, ni información acerca de quien fue Namuncurá ni los pueblos indígenas en general ni en particular en el período del avance estatal en la segunda mitad del siglo XIX. No hay mención a los territorios ni a los objetivos de las campañas militares. El origen de Puan parece formar parte de una cadena evolutiva, un génesis no enmarcado en un proceso histórico, sino en un origen per se desligado de la historia local, regional y nacional. En esa operación descontextualizadora los indígenas son abordados en salas contiguas, pero no ya como actor social del presente sino como objeto arqueologizado, dado que existen referencias a sus culturas en la sala denominada "Arqueología".

Por cuestiones de espacio, dicha sala oficia también como pasillo entre el museo y la Dirección de Cultura. La mayor parte de la colección se encuentra en un mobiliario vidriado que reúne distintos objetos y datos. En la esquina de la vitrina hay un ñandú embalsamado (muerto en la isla por comer una bolsa de nylon) y se marca que este animal era la comida preferida dentro de la dieta de los indígenas.

Hay también un indígena dibujado en tamaño real en cartón, con poncho e hilando con lana de oveja. Hay referencias a la vestimenta, a la medicina y a los hábitos funerarios. También elementos donados, un poncho de lana y una foto de Manuela Pichifilo, mapuche que no era de Púan, madre de Aolinda Montiel quien sí reside en dicha ciudad y donó las herramientas de tejido que Manuela utilizaba y ella misma había confeccionado.

Algunas referencias o datos no son precisos, ya que no refiere a un pueblo en particular sino a los indígenas en general. Así se encuentran algunos carteles que aseguran: "Creían que el difunto cambiaba de cuerpo, por lo que ponían en la tumba, carne, yerba, tabaco y sal para emprender el viaje". Otras menciones tomadas de Sarramone (1993) hacen hincapié en una actividad o práctica cultural exclusiva de manera tajante: "Los pampas antes de la aparición del caballo, se dedicaban a la cerámica"; "Se pintaban el rostro tanto en la guerra como en las ceremonias, y algunos usaban el tembetá" sin explicación alguna acerca de este elemento y el contexto de su utilización.

Existe un claro predominio de elementos líticos dentro de la colección exhibida en la vitrina. Entre ellos, morteros, instrumentos, puntas de flecha, bolas perdidas (no comunes en la zona) y precisas referencias sobre los lugares donde se encontraron, la mayoría en excavaciones realizadas en la laguna de Púan, entre 1988 y 1990 (Oliva et. al. 1991). También hay información que destaca el nomadismo de las sociedades indígenas.

Al lado de la estantería vidriada, el museo expone una cuna pampa, elementos de molienda y un telar. Frente a ellas un mueble sostiene en alto tres réplicas de lanzas indígenas. La mayoría de los objetos provienen de donaciones por parte de particulares, de allí el eclecticismo de las colecciones que algunas salas de los museos de frontera proponen al momento de organizar las muestras.

Otra particularidad del museo Ignacio Balvidares es que de un total de cuatro salas, dos de ellas están dedicadas a la arqueología. Una es la que ya se ha descripto y la otra es el último recinto del establecimiento, la sala "de Arqueología F. Yannarella". Su motivo y denominación obedece al trabajo que el arqueólogo Francisco Yannarella llevó a cabo en la isla de Puan en la década de 1970, cuando obtuvo un importante material que donó al museo.

El material expuesto en dicha sala está compuesto por tallados en piedra y restos óseos de fauna autóctona. Según los arqueólogos, la importancia de la laguna de Puan surge porque es el único lugar de la Provincia de Buenos Aires en el que fue encontrado un escondrijo o reservorio de materia prima, actualmente exhibido en el Museo. Está constituido por un conjunto de instrumentos denominados raederas para cortar y un núcleo de casi diez kilos. El material es de riolita, piedra que aflora en las Sierras del partido de Saavedra, a 70 kilómetros de distancia y a partir de este dato, según los investigadores, justificaría el nomadismo de los grupos humanos que allí habitaban ${ }^{10}$.

El análisis de la organización de las colecciones y las salas del museo Ignacio Balvidares permite entender que se han priorizado dos grandes períodos: 1) Su origen como campamento militar en el marco de la lucha contra el indio

\footnotetext{
10 Información publicada en "Puan formará parte de un documental televisivo". Semanario Perfiles, 29 de marzo de 2011. en http://www. perfilespuan.com.ar visita del 27/07/2011.
} 
y su posterior "evolución" y 2) Un pasado remoto donde el material exhibido proviene de donaciones y trabajo arqueológico. Así, el resultado es ecléctico y poco preciso en cuanto a su aporte a la comprensión de las distintas etapas y culturas que allí residieron.

A diferencia de Trenque Lauquen, no existe una comunidad indígena organizada que pueda cuestionar el mito de la extinción de estas sociedades por motivos de evolución natural. Las pocas caracterizaciones sobre el indígena son indirectas, como detalles de la historia, siempre a punto de desaparecer y señalándolo como un actor social inspirado por la violencia, la barbarie y el constante asedio y ataque a los pioneros y militares.

El indígena es representado como un peligroso obstáculo de la civilización, a punto de "caerse" de la historia o como un agente prehistórico abordable por la arqueología, por tanto, partícipe de una etapa prematura para la ingerencia de la historiografía.

En suma, el museo de Puan pondera la colección de armas, fotos y objetos antiguos en su salón principal, titulado "Evolución de un pueblo" para luego disponer de tres recintos, en los cuales en uno, el paleontológico, el protagonista es un gliptodonte; en otro el material lítico hallado en la isla de Puan y en el restante, conviven eclécticos objetos e imprecisas informaciones acerca de poblaciones indígenas sin tiempo, sin lugar y sin historia. De modo que el aporte del Ignacio Balvidares para la comprensión de los procesos históricos que enmarcan la fundación de la comandancia de Puan, de las relaciones interétnicas que allí se daban y de los pueblos que habitaban la región, es nulo.

Como ha señalado Blengino, la teoría evolucionista claramente observable en el Balvidares a través de sus salas- encuentra en Pampa y Patagonia (y agregamos en el oeste bonaerense) un depósito de restos, un escenario de la prehistoria casi intacto, una oposición historiaprehistoria, hombre moderno-hombre de las cavernas, como justificación de las campañas al desierto, alimentada de pretextos científicos. Lo que concierne al indio, a la naturaleza que lo circunda y su misma presencia se anulan, pues remiten a un anacronismo (Blengino 2005).

El indígena es concebido por los museos de frontera como un actor social en extinción, una pieza propia del museo, que mediante una operación arqueológica es trasladado a eras prehistóricas, evitando así el abordaje de su sometimiento por parte de los pioneros fundadores.

\section{Recapitulación}

A partir del análisis de los museos de la "última frontera" hemos podido establecer una serie de particularidades vinculadas a la construcción de la historia local y al mismo tiempo, develar ciertos tópicos comunes inscriptos en las narrativas nacionalistas (Delrio 2005).
Con mayor o menor énfasis, los establecimientos exhiben colecciones que no en pocas ocasiones sistematizan un relato de abnegación y sacrificio por parte de pioneros inmigrantes, atemorizados por el latente ataque de los salvajes y bárbaros pueblos indígenas. Éstos, siempre son mencionados como origen del problema y responsables de ataques que debieron ser repelidos por aquellos hombres nobles que solo pretendían poblar la llanura bonaerense.

A su vez, en algunos casos, el abordaje de esos procesos es pobre y escueto y, en otros ni siquiera problematizado. Colecciones que remiten al indígena al pasado, manifiestan una paleontologización o arqueologización de los aborígenes, sobre los cuales lo poco que se dice siempre gira en torno de su extinción, salvajismo y en ocasiones con información errónea, como la foto que en el museo de Puan asegura tratarse de Pichihuincá, o incompleta, como puede observarse en Trenque Lauquen y la vasija de Huitru Loo.

Evidentemente, como se ha expuesto en el propio análisis de cada uno de los museos, dichas instituciones devienen en agentes funcionales a la cristalización de discursos hegemónicos acerca de las sociedades indígenas, la historia de cada uno de los pueblos y no en menor medida, de la historia del estado nacional argentino.

Entendemos que a este tipo de relato contribuye la presentación de objetos de distinta procedencia, mostrando no tanto lo que se quisiera sino más bien lo que se encuentra disponible. Los museos de la región, salvo excepciones, se nutren y se renuevan de acuerdo a las donaciones que particulares fueron realizando a lo largo de la existencia del establecimiento. El resultado, como puede suponerse, no logra despegarse de un eclecticismo que intenta ser subsanado con criterios de organización de las salas, que no siempre logran su cometido.

La perdurabilidad de discursos exhibidos desde hace décadas atrás, mal pueden ser modificados, en lugares como Puan y otras ciudades de la ex frontera, donde la agencia de un sector subalterno indígena es inexistente. Más sorprendente resulta este tipo de discursos en Trenque Lauquen, donde aún existiendo una comunidad indígena organizada, esto no alcanza para propiciar una revisión de un museo que organiza sus salas en sentido cronológico y evolutivo, ubicando la sala aborigen entre la prehistoria y la colonia. Incluso es más llamativo que la lectura de la cartelería invite a sostener la extinción del indígena, argumento basado en estudios publicados hace medio siglo y que a pesar de las invitaciones extendidas por las autoridades a los descendientes del entronizado cacique Pincén, no se promueva el reconocimiento de una realidad que los discursos internalizados en el imaginario colectivo, reiteran de manera sistemática.

De modo que si a priori pensábamos que la presencia 
de una comunidad indígena organizada en una de las ciudades de la última frontera (Trenque Lauquen) implicaba una clara diferencia respecto a Puan, ya que podría impugnar ciertos relatos exhibidos en su museo, el relevamiento y análisis de las colecciones echaron por tierra dicha suposición, aunque en Trenque Laquen la agencia de la Cacique Pincén hace emerger con mayor contundencia las contradicciones de los discursos hegemónicos presentados.

Claramente, el poder de ciertos postulados institucionalizados en los museos y acompañados desde festejos, textos y programas escolares, aún se siguen imponiendo por sobre la agencia de los indígenas, empecinados en sostener algo tan evidente como simple, "estamos vivos".

Munro, 15 de agosto de 2012

\section{Bibliografía}

Alonso, A. M. 1988. The effects of the Truth: Representation of the Past and the Imagining of Community. Journal of Historical Sociology 1(1): 33-57.

Barba, F. 1977. La zanja de Alsina, la ofensiva olvidada. En Actas del Tercer Congreso de Historia Argentina y Regional, Bs. As., Academia Nacional de Historia.

Blasco, M. E. 2007. Los museos históricos en la Argentina entre 1889 y 1943. En XI Jornadas Interescuelas/Departamentos de Historia, San Miguel de Tucumán.

Blengino, V. 2005. La Zanja de la Patagonia. Los nuevos conquistadores: Militares, científicos, sacerdotes y escritores, capítulo 1, pp. 29-61. Fondo de Cultura Económica, Buenos Aires.

Casamiquela, R. 1969. Un nuevo panorama etnológico del área panpampeana y patagónica adyacente. Pruebas etnohistóricas de la filiación tehuelche septentrional de los Querandies. Museo Nacional de Historia Natural. Santiago de Chile.

Delrio, W. 2005. Memorias de expropiación. Sometimiento e incorporación indígena en la Patagonia 1872-1943. Editorial de la Universidad Nacional de Quilmes.

Estévez, J. J. 2011. Pincén: Vida y Leyenda. Editorial Biblos, Buenos Aires.

Farro, M. 2009. La formación del Museo de la Plata. Coleccionistas, comerciantes, estudiosos y naturalistas viajeros a fines del siglo XIX. Prehistoria Ediciones, Rosario.

Lazzari, A. y Lenton, D. 2000. Etnología y Nación: facetas del concepto de Araucanización. Avá. Revista de Antropología 1: 125-140.

Lenton, D. 2005. “De centauros a protegidos. La construcción del sujeto de la política indigenista argentina desde los debates parlamentarios $(1880-1970) "$. Facultad de Filosofía y Letras, Universidad de Buenos Aires, Argentina, Tesis Doctoral, 595 pp.
Mandrini, R. y Ortelli, S. 1995. Repensando viejos problemas: observaciones sobre la araucanización de las pampas. En: Runa XXII, Buenos Aires, pp. 135-150.

Mases, E. H. 2002. Estado y cuestión indígena: El destino final de los indios sometidos en el sur del territorio (1878-1910). Prometeo libros/ Entrepasados, Buenos Aires.

Mayo, F. J. 2003. Un titán del desierto. Gral. Conrado Villegas. Editado bajo la responsabilidad de Honorable Cámara de Diputados de la Provincia de Buenos Aires.

Moyano, A. 2007. Crónicas de la Resistencia mapuche. Bariloche, Edición del autor

Nagy, M. 2008. ¿No tan distintas? La construcción de la identidad bonaerense a través de los relatos históricos y la celebración de actos fundacionales en Trenque Lauquen y Pigüé. En Segundas Jornadas de Historia Regional del Oeste Bonaerense, Trenque Lauquen, 25 y 26 de abril.

Navarro Floria, P. 2001. El salvaje y su tratamiento en el discurso político argentino sobre la frontera sur, 1853-1879. Revista de Indias Vol. LXI, $\mathrm{N}^{\circ} 222$ (mayo-agosto 2001): 345-377.

Navarro Floria, P. 2007. Paisajes de un progreso incierto. La Norpatagonia en las revistas científicas argentinas (1876-1909). En Navarro Floria, Pedro (coord). Paisajes del Progreso. La resignificación de la Patagonia Norte, 1880-1916, capítulo 1, pp. 13-77. EDUCO, Univ. Nacional del Comahue, Neuquén.

Papazian, A y Nagy, M. 2009. De la Isla como Campo. Prácticas de disciplinamiento indígena en la Isla Martín García hacia fines s. XIX. XII Jornadas Interescuelas-Departamentos de Historia. Universidad Nacional del Comahue. San Carlos de Bariloche, Río Negro.

Pinto Aparicio, B. 2005. La "Conquista al Desierto". Un lugar para la discusión de las ideas políticas en Argentina. 1880- 2000. En Jornadas de Humanidades e Historia del Arte, Universidad Nacional del Sur, Bahía Blancal

Podgorny, I. y Lopes, M. 2008. El desierto en una vitrina: Museos e historia natural en la Argentina, 1810-1890. México: Limusa.

Podgorny, I. 2005. La mirada que pasa: museos, educación pública y visualización de la evidencia científica. Historia, Ciéncias, SaúdeManguinhos12, suppl. 231-264.

Pupio, M. A. 2005. Coleccionistas de objetos históricos, arqueológicos y de ciencias naturales en museos municipales de la provincia de Buenos Aires en la década de 1950. História, Ciências, Saúde - Manguinhos, 12, suppl., 205-229.

Rosso, A.1991. En Argentina, un museo de padre único. Museum, volumen $172, N^{\circ} 4$, pp. 242-244.

Sarramone, A. 1993. Catriel y los indios Pampas de Buenos Aires. Editorial Biblos Azul, Azul, Argentina.

Semadeni, P. 2010. Trenque Lauquen, seis estudios de historia, capítulo 5, pp. 221-237. Editorial Zahir, Buenos Aires. 